Check for updates

Cite this: RSC Adv., 2020, 10, 42267

Received 2nd September 2020 Accepted 4th November 2020

DOI: $10.1039 / d 0 r a 07540 j$

rsc.li/rsc-advances

\section{Nano-hydroxyapatite/polyaniline composite as an efficient sorbent for sensitive determination of the polycyclic aromatic hydrocarbons in air by a needle trap device $\dagger$}

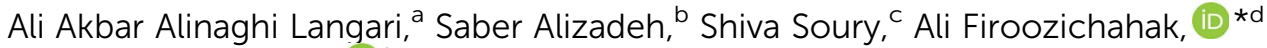 \\ Davood Nematollahi, (D) ${ }^{b}$ Parsa Mohammad Alizadeh ${ }^{a}$ and Nasim Sanae ${ }^{e}$
}

Hydroxyapatite is a readily available, inexpensive, environmentally friendly adsorbent with high adsorption capacity. In this study, a polyaniline-doped nano-hydroxyapatite (PANI@HA) adsorbent was synthesized and employed in a needle trap device for the extraction of polycyclic aromatic hydrocarbons such as naphthalene, fluoranthene, benzo[a]anthracene, phenanthrene, and benzo[a]pyrene for the first time. The synthesized adsorbent was characterized by X-ray diffraction, field emission scanning electron microscopy, and Fourier-transform infrared spectroscopy analysis. Initially, effective variables such as the carryover effect, storage time, accuracy, and precision of the method were examined in the laboratory. The desorption conditions were optimized using the response surface methodology and central composite design methods. From the standpoint of quantitative parameters, the limit of detection and limit of quantitation were determined to be between 0.001 and 0.003 and 0.021 and $0.051 \mathrm{ng} \mathrm{mL}^{-1}$, respectively, which indicates the high sensitivity of the proposed method. Additionally, no significant changes were detected after storage of analytes inside the needle at $4{ }^{\circ} \mathrm{C}$ after 60 days. The results of this study also provide a high correlation between the results of sampling with needles containing PANI@HA and with XAD-2 adsorbent tubes (standard NIOSH 5115 method) $\left(R^{2}=0.98\right)$. Finally, the proposed method was successfully employed in the extraction and determination of polycyclic aromatic hydrocarbons in field (real) samples. In general, it can be concluded that a needle packed with PANIaHA is a reliable and high-performance method for sampling polycyclic aromatic hydrocarbons compared to the NIOSH method.

\section{Introduction}

Polycyclic aromatic hydrocarbons (PAHs) are a large group of organic compounds with at least two aromatic rings. These compounds can be obtained by incomplete pyrolysis of organic matter, which mainly originates from power plants, car engine outlets, cigarette smoke, and tobacco. ${ }^{1}$ To date, several PAHs, such as benzo $[a]$ pyrene, have been classified as carcinogenic. ${ }^{2-4}$

${ }^{a}$ Student Research Committee, School of Public Health, Bam University of Medical Sciences, Bam, Iran

${ }^{b}$ Department of Chemistry, Bu-Ali-Sina University, Hamedan, Iran

${ }^{c}$ Department of Occupational Health Engineering, School of Public Health, Ilam University of Medical Sciences, Ilam, Iran

${ }^{d}$ Department of Occupational Health, Faculty of Health, Social Determinants of Health Research Center, Gonabad University of Medical Sciences, Gonabad, Iran. E-mail: a. firoozi@edu.umsha.ac.ir

${ }^{e}$ Center of Excellence for Occupational Health, Occupational Health and Safety Research Center, School of Public Health, Hamadan University of Medical Sciences, Hamadan, Iran

$\dagger$ Electronic supplementary information (ESI) available. See DOI: 10.1039/d0ra07540j
OSHA has stated that the permissible limits for naphthalene, phenanthrene, and benzo[a]pyrene are 50.0, 0.2 and $0.2 \mathrm{mg}$ $\mathrm{m}^{-3}$, respectively. Due to the carcinogenicity of these compounds, the introduction of a highly sensitive and efficient method for the determination of these pollutants in air is an important scientific goal. To date, different methods have been introduced for the sampling and analyzing of PAH compounds. NIOSH and OSHA are the recommended methods for the sampling of $\mathrm{PAH}$ compounds. In these methods, the extraction and preparation steps after the sampling process depend on the applied solvent. From the eco-friendly standpoint, large volumes of solvents are required for extraction, washing and recovery of the adsorbent, which can be expensive, toxic, carcinogenic, and hazardous to the environment and human health. ${ }^{5,6}$ In this regard, attention to solvent-free methods has increased significantly. Recently, the solid phase microextraction (SPME) and needle trap device (NTD) techniques as solvent-free methods have been widely considered by researchers. ${ }^{7-9}$ To date, various reports have been published on the SPME technique for the sampling and extraction of PAH 
compounds in different matrices. ${ }^{\mathbf{1 1 0 - 1 3}}$ Despite the mentioned advantages, this method has some drawbacks, such as fiber fragility and limited fiber capacity. The needle trap device (NTD) was first introduced by Pawliszyn in $2001 .{ }^{14}$ Simple and rapid sampling of the pollutant in an unbalanced manner are the prominent features of the solvent-free NTD technique. ${ }^{\mathbf{1 4 5}}$ Also, in the needle trap sampling method, more adsorbent can be placed inside the NTD, which increases the absorption capacity. ${ }^{\mathbf{1 4 1 6}}$ The type of adsorbent employed in the NTD is very effective in determining its performance. Various commercial and synthetic adsorbents have been investigated in different studies. ${ }^{17-20}$ To the best of our knowledge, one efficient adsorbent that has not been used in NTDs is nano-hydroxyapatite particles (nHA). Hydroxyapatite (HA), with the chemical formula $\left(\mathrm{Ca}_{10}\left(\mathrm{PO}_{4}\right)_{6}(\mathrm{OH})_{2}\right)$ and $\mathrm{Ca} / \mathrm{P}=1.67$, is the main calcium phosphate material found in biological tissues such as vertebrae and teeth. Due to its chemical and structural similarity to bone mineral, it has been used in this sector in the medical field. $^{21}$ The remarkable properties of nHA, such as high absorption capacity, biocompatibility, high stability in oxidation and reduction conditions, multiple interactions, low-cost preparation, non-toxicity, and high sensitivity, have attracted the attention of many scientists, including analytical chemists and environmental researchers. ${ }^{22}$ Compared to the other existing commercial adsorbents, nHA has provided new insight into sampling of analytes due to its small size, high surface area, low density, and high surface-to-volume ratio. Also, thermal stability is one of the unique features of this adsorbent; unlike metal-organic framework adsorbents, ${ }^{23,24}$ it can withstand high temperature conditions of up to $1450{ }^{\circ} \mathrm{C}^{25,26} \mathrm{nHA}$ and its derivatives are well-known as adsorbents for many compounds due to the presence of two $\mathrm{C}$ and $\mathrm{P}$ ionic bonds on their surfaces and the presence of cationic and phosphate ions. nHA has been used as a solid phase in high-efficiency liquid chromatography (HPLC), ${ }^{27,28}$ solid-phase extraction, ${ }^{29-31}$ chemical sensors and micro-solid phase extraction..$^{22,32,33}$ However, researchers are attempting to optimize and enhance these remarkable abilities by building new HA nanoparticle composites. To strengthen the structural stability and increase the surface area of the adsorbents, a wide range of materials have been used. Recently, polyaniline (PANI) has been reported in studies. ${ }^{34}$ Because of its simple synthesis, high electrical conductivity, and long-term environmental stability, polyaniline is a potential candidate to be employed as a composite in the hydroxyapatite structure. ${ }^{35}$ The suitable interaction tendency of these materials is an important parameter. ${ }^{36}$ HA can have good chemical affinity with polyaniline. Moreover, interaction of polyaniline with nHA leads to increased mechanical strength, enhanced chemical stability and higher surface area. ${ }^{37}$ To the best of our knowledge, there is no study about the use of hydroxyapatite particles in NTDs for air pollution sampling. Additionally, polyanilinedoped nano-hydroxyapatite (PANI@HA) has not been used in any matrix for the sampling of PAHs. According to this background, in the present study, we attempted to use a PANI@HA composite adsorbent packed in a needle trap device for sampling and analyzing aromatic polyhydrocarbons (naphthalene, fluoranthene, benzo[a]anthracene, phenanthrene, and benzo[a]pyrene) by GC-FID. Optimization of the adsorption conditions (temperature and time) was performed using the statistical response methods of response surface methodology (RSM) and central composite design (CCD). In order to verify the performance of the NTD:PANI@HA method, analytical parameters such as the limit of detection (LOD), limit of quantification (LOQ), and linear dynamic range (LDR) were evaluated. Finally, the performance of NTD:PANI@HA was examined in real time.

\section{Materials and methods}

\subsection{Chemicals and reagents}

In this study, benzo[a]pyrene (99.2\%), phenanthrene (99.8\%), naphthalene $(99.9 \%)$, fluoranthene $(99.3 \%)$, benzo[a]anthracene (99.2\%), calcium chloride $\left(\mathrm{CaCl}_{2}\right)$ (98\%), diammonium hydrogen phosphate $\left(\left(\mathrm{NH}_{4}\right)_{2} \mathrm{HPO}_{4}\right)(99 \%)$, potassium dihydrogen phosphate $\left(\mathrm{KH}_{2} \mathrm{PO}_{4}\right)(98 \%)$, ammonium peroxydisulfate $\left(\left(\mathrm{NH}_{4}\right)_{2} \mathrm{~S}_{2} \mathrm{O}_{8}\right)(99 \%)$, acetic acid (99.8\%), hydrochloric acid (98\%), sodium hydroxide (98\%), and aniline (99\%) were obtained from Sigma-Aldrich and used without any purification. Also, high purity nitrogen (99.99\%) was obtained from Raham Company (Tehran, Iran).

\subsection{Instruments}

In this study, we used a 22-gauge (G) spinal needle (outer diameter $0.71 \mathrm{~mm}$ and a length of $90 \mathrm{~mm}$ ) obtained from Kosan (Tokyo, Japan). A sampling pump (SKC 222 series, PA, USA) with a flow rate of 1-200 $\mathrm{mL} \mathrm{min}^{-1}$ was connected to the NTD packed with PANI@HA. The XAD-2 adsorbent tubes (100 mg/50 mg) were obtained from the SKC for the sampling of the PAH compounds according to the NIOSH 5515 standard method. A magnetic hot plate (TAT-94-1062) (Tehran-Iran) was employed to heat the samples during the extraction process. Also, a $3.0 \mathrm{~mL}$ Luer-Lok syringe (Mina Tajhiz-Tehran) was applied to inject the carrier gas (nitrogen). A balancing scale (model BP-121s, Germany) was employed to weigh the analytes. A three-mouth flask was used to obtain certain concentrations of the analytes. Additionally, a digital thermometer (Testoterm $\mathrm{GmbH}$ ) was set up for continuous monitoring of the inside temperature of the glass container. To investigate the crystal structure and purity of synthesized PANI@HA, the X-ray diffraction technique was performed with a Rigaku Ultima device made in Japan in transmission mode using $\mathrm{Cu} \mathrm{K} \alpha$ radiation at $2 \theta=5-80$. A fieldemission scanning electron microscope (FE-SEM, TESCAN Mira, Czech Republic) was employed for the morphology investigation. To confirm the functional groups in the synthesized structure of the adsorbent, a Fourier-transform infrared (FT-IR) spectrometer (Perkin Elmer, USA) was used.

\subsection{Gas chromatography specifications}

A Varian CP-3800 gas chromatograph with an FID detector equipped with a CP7462 column $(30 \mathrm{~m} \times 0.25 \mathrm{~mm})$ was used for the separation of the PAH compounds. To study the thermal desorption of the $\mathrm{PAH}$ compounds, the temperature of the injection site was adjusted in the range of $270-390{ }^{\circ} \mathrm{C}$. The GC was set up with a split-less liner, column flow of $1.6 \mathrm{~mL} \mathrm{~min}^{-1}$, and injection port pressure of 8.85 psi. Moreover, high purity 
nitrogen was used as a carrier gas at a flow rate of $1.6 \mathrm{~mL} \mathrm{~min} \mathrm{~m}^{-1}$. The oven temperature program started at $80{ }^{\circ} \mathrm{C}$ and then reached $160{ }^{\circ} \mathrm{C}$ with a rate of $25^{\circ} \mathrm{C}$ per minute. The temperature was then increased to $300{ }^{\circ} \mathrm{C}$ with a rate of $30{ }^{\circ} \mathrm{C}$ per minute and maintained at this temperature for $2 \mathrm{~min}$. Finally, the temperature of the detector was set to $325^{\circ} \mathrm{C}$.

\subsection{Response surface methodology}

Response surface methodology (RSM) is a set of mathematical methods that determines the relationships between one or more response variables and several independent variables. Box and Wilson introduced this method in 1951. It is still used as a test design tool. In designing experiments, the goal is to identify and analysis the variables affecting the outputs with the fewest experiments. The response level method is a mathematical-statistical method for optimizing test outputs. In this study, the number of experiments was determined using response surface methodology (RSM) and central composite design (CCD). The software estimates the optimal point using eqn (1), in which $Y$ represents the model prediction, $B_{0}$ is the constant-coefficient, $B_{i}$ is the linear coefficient, $B_{i j}$ is the interaction coefficient between the variables, $X$ is the variable and $\varepsilon$ is the residual amount. ${ }^{38}$

$$
Y=B_{0}+\sum_{i=1}^{k} B_{i} X_{i}+\sum_{1<i<j}^{k} B_{i j} X_{i} X_{j}+\varepsilon
$$

\subsection{Adsorbent synthesis procedure}

2.5.1 nHA synthesis procedure. The employed nanohydroxyapatite (nHA) in this study was synthesized by the reaction of $\mathrm{CaCl}_{2}$ with $\left(\mathrm{NH}_{4}\right)_{2} \mathrm{HPO}_{4}$ based on previously reported studies. ${ }^{35}$ Briefly, $100 \mathrm{~mL}$ of $\left(\mathrm{NH}_{4}\right)_{2} \mathrm{HPO}_{4}$ solution $(0.4 \mathrm{M})$ was stirred at room temperature, and then $100 \mathrm{~mL}$ of $\mathrm{CaCl}_{2}$ solution $(0.6 \mathrm{M})$ was added dropwise to produce a white precipitate. The $\mathrm{pH}$ of the reaction medium was adjusted and maintained at $10.0-11.0$ by adding $\mathrm{NaOH}(0.1 \mathrm{~N})$ solution during the reaction period. The obtained powder was rinsed three times with distilled water for removal of the remaining salts. The resulting precipitate was aged at temperatures of 24$90{ }^{\circ} \mathrm{C}$ for 24 hours and stored at room temperature.

2.5.2 PANI synthesis procedure. Polyaniline (PANI) was prepared according to previous studies. ${ }^{39}$ First, $20.4 \mathrm{~g}$ of freshly distilled aniline monomer was dissolved in $230.0 \mathrm{~mL} \mathrm{HCl}(1.5$ $\mathrm{M})$, and the resulting solution was cooled to below $5{ }^{\circ} \mathrm{C}$ for 1 hour. Also, $25.0 \mathrm{~g}$ of ammonium peroxydisulfate was dissolved in $250 \mathrm{~mL}$ of $\mathrm{HCl}(1.5 \mathrm{M})$. The pre-cooled solution was slowly added to the second solution. The reaction temperature was maintained at $0-5{ }^{\circ} \mathrm{C}$ for $4 \mathrm{~h}$. The obtained dark green precipitate was thoroughly washed with distilled water. PANI was obtained as a dark green powder after drying at $40{ }^{\circ} \mathrm{C}$ for 48 hours.

2.5.3 PANI@HA synthesis procedure. For the preparation of the PANI@HA composite, $5.0 \mathrm{~g}$ of synthesized polyaniline was added to $100.0 \mathrm{~mL}$ of ethanol in a three-neck open flask with a temperature of $70{ }^{\circ} \mathrm{C}$. After complete dissolution of polyaniline, $2.9 \mathrm{~g}$ of synthesized nHA slurry (75.0 wt $\%$ nHA) was added to the solution. The mixture was heated and stirred for 2 hours at $70{ }^{\circ} \mathrm{C}$. When the reaction completed, the resulting mixture was aged at room temperature for 24 hours and then thoroughly washed with deionized water and ethanol. The obtained PANI@HA composite was placed in a vacuum oven at $70{ }^{\circ} \mathrm{C}$ for 48 hours. By changing the weight ratio of nHA slurry, the nHA ratio in the final composite could be changed. ${ }^{\mathbf{4 0 , 4 1}}$

\subsection{Sampling chamber}

The sampling chamber is shown in Fig. 1. In this study, a threemouth flask $(250 \mathrm{~mL})$ was used for the sampling of $\mathrm{PAH}$ compounds. First, for the preparation of different concentrations of analytes, all three-glass flask openings were closed. Amounts of $0.5-10.0 \mathrm{mg}$ of the analytes were placed in the chamber at different times. Sampling began after the container was placed on the heater at $120{ }^{\circ} \mathrm{C}$ for 30 minutes. One of the paths in the glass flask was intended to allow entrance of fresh air and prevent vacuuming. The second path was used for the sampling of $\mathrm{PAH}$ compounds by the XAD-2 adsorbent tube (according to the NIOSH 5515 method). Finally, the third path was employed for the sampling of the analytes by the proposed NTD method. It should be noted that the sampling process was performed using the NIOSH and NTD methods simultaneously.

\subsection{Preparation of NTD}

In this study, gauge 22 medical spinal needles (O.D. $0.71 \mathrm{~mm}$, I.D. $0.39 \mathrm{~mm}$ ) were employed to fabricate the NTDs. The needle was packed with $1.0 \mathrm{mg}$ of PANI@HA adsorbent and $1.0 \mathrm{mg}$ of crushed glass particles (to prevent NTD blockage). Preliminary tests showed that no absorption occurred on the crushed glass. Both sides of the adsorbent inside the needle were closed with $3.0 \mathrm{~mm}$ glass wool, and a free gap of $5.0 \mathrm{~mm}$ was considered after the second layer of glass wool. The packed NTDs were connected to a low-flow sampling pump, and the flow rate was measured using a soap bubble flow meter. The optimum flow rate of $3.0 \mathrm{~mL}$ per minute was selected for sampling by the NTD method.

\subsection{Desorption parameters}

In this study, the desorption temperature was investigated in the range of $270-390{ }^{\circ} \mathrm{C}$. The minimum temperature that creates the maximum peak area was selected as the optimal temperature for subsequent analyses. Also, the NTD was placed into the injection section of the GC for 3 to 12 minutes to measure the optimal desorption time. The temperature and desorption time were optimized using Design-Expert software version 10. The NTD with a Luer-Lok syringe was inserted into the injection site according to the specified desorption time range (3-12 minutes). After the desorption time, the carrier gas (nitrogen) was passed through the analytes and entered the GC column for detection of the values.

\subsection{Method validation}

The LOD, LOQ, and LDR parameters were assessed for validation of the NTD performance. To obtain the LOD and LOQ, a diluent was employed to reduce the known concentration of the analyte. The 




Fig. 1 The scheme of the sampling chamber: (1) sampling pump (SKC Universal 44XR, USA) by the NIOSH 5515 method. (2) Sampling pump (SKC 222-3, USA) by the NTD:PANI (aHA method. (3) A three-mouth flask. (4) Magnetic heater. (5) The needle trap device (gauge 22).

diluent was injected into the device each time to reach the desired concentrations at which the height of the obtained peak from the analysis was 3 and 10 times the background peak, respectively. Also, the LDR, which is an important analytical performance parameter, was investigated. To determine the accuracy of the results obtained by the NTD, side-by-side sampling was performed using the NTD and the standard method for each combination. In this section, the NIOSH 5515 method was used for sampling of the mentioned compounds. The accuracy of the concentration range was 0.5 to 2 times the allowable exposure limit.

\subsection{Carryover measurement}

After sampling, to determine the carryover value, the heating of absorption was performed in the injection section of the GC device at the specified times (3-12 minutes) again. The obtained peak ratios (of the second absorption to the first absorption) were expressed in terms of percentage to calculate the carryover values at the different times.

\subsection{Determining precision}

The precision of the measurements was calculated to determine the repeatability and reproducibility of the proposed method. To express the precision, the relative standard deviation index (RSD) was calculated. To calculate the repeatability, sampling was performed with an NTD at different concentration levels (5 different concentrations). The reproducibility was determined by sampling with three similar NTDs at one concentration.

\subsection{Breakthrough volume}

The breakthrough volume (BTV) is an important factor in preventing gross measurement errors. For this purpose, two NTDs packed with equal amounts of the studied adsorbent were connected by a linker tube. After the sampling process, the second NTD was injected into the GC, and the remaining analytes on the adsorbent bed were examined.

\subsection{Determination of storage stability}

For the determination of storage stability, certain concentrations of the mentioned analytes (naphthalene at a concentration of $50.0 \mathrm{mg}$ $\mathrm{m}^{-3}$; phenanthrene, benzo $[a]$ pyrene, fluoranthene and benzo $[a]$ anthracene at a concentration of $0.2 \mathrm{ng} \mathrm{mL}^{-1}$ ) were sampled by the NTD under the optimal sampling conditions. The analysis process was performed over 1 to 60 days at laboratory $\left(25^{\circ} \mathrm{C}\right)$ and refrigerator $\left(4{ }^{\circ} \mathrm{C}\right)$ temperatures. To store the samples, the NTD was covered with a septum and then stored for a specified period.

\subsection{Field measurement}

For evaluation of the proposed NTD in real conditions, 10 samples of regional air with high traffic and congestion of gasoline vehicles were sampled by NTD:PANI@HA. Finally, the results obtained with the XAD-2 adsorption tube were compared with the collected data from the NTD packed with PANI@HA.

\section{Results and discussion}

\subsection{Characterization of the PANI@HA composite}

The X-ray diffraction pattern presented in Fig. 2 is consistent with the previously reported data and shows the suitable

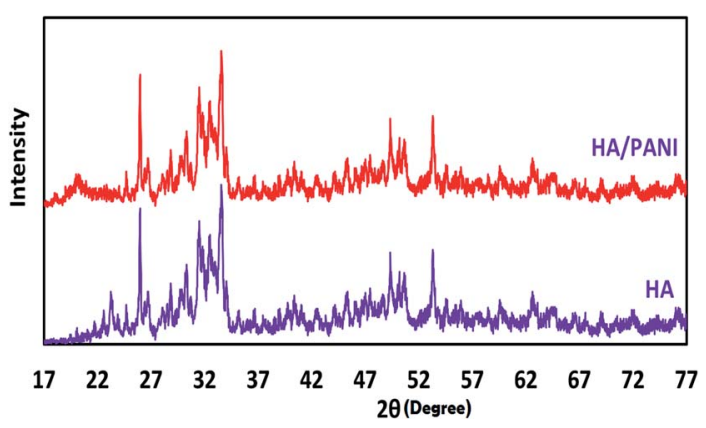

Fig. 2 PXRD patterns of the $\mathrm{nHA}$ and PANI@HA structures. 



Fig. 3 FE-SEM images of (a) $\mathrm{nHA}$ and (b) PANI@HA structures.

crystallinity and successful synthesis of the PANI@HA adsorbent. The distinguished diffraction peaks can be assigned as hexagonal phase, consistent with the standard pattern of HA. ${ }^{34,36}$ The XRD pattern of nHA indicates the existence of all characteristic peaks at $2 \theta=25.99,31.77,33.18,35.16,49.43$ and $54.66^{\circ}$. These results prove the purity and suitable crystallinity of the synthesized nHA. In other words, calcium oxide and tricalcium phosphate were not detected. These results are consistent with previously reported studies. ${ }^{34,36}$ However, the broad shoulder at $2 \theta=20.44^{\circ}$ corresponding to PANI cannot be seen clearly in the XRD patterns of the composites because the diffraction peaks of PANI are weak and are covered by the background of the HA peaks. ${ }^{36}$

To investigate the synthesis and morphology of the prepared PANI@HA composites, FE-SEM analysis was performed. According to Fig. 3(a), the synthesized HA consists of unique flake-like structures. Fig. 3(b) indicates that the flake-like HA structures are doped with spherical agglomerates of PANI particles.

To confirm the formation of functional groups in the PANI@HA structure, the FT-IR spectra of HA and the PANI@HA composite were recorded. Fig. 4 indicates the FT-IR spectra of pure HA and the PANI@HA structures. The FT-IR spectrum of HA shows the specific peaks corresponding to the phosphate bending vibration mode $\left(567,603 \mathrm{~cm}^{-1}\right)$, phosphate stretching vibration mode $\left(963 \mathrm{~cm}^{-1}\right)$, and phosphate stretching vibration mode $\left(1035,1101 \mathrm{~cm}^{-1}\right)$. The FT-IR spectrum of the PANI@HA composite shows the specific bands of HA and PANI. The characteristic bands at 1301 and $1147 \mathrm{~cm}^{-1}$ can be assigned to the stretching mode of $\mathrm{C}-\mathrm{N}$ in $\mathrm{Ar}-\mathrm{N}\left(1301 \mathrm{~cm}^{-1}\right)$, respectively. However, the intensity of the PANI peaks is relatively weak due to the low mass content and interaction with the composite..$^{37,42}$

\subsection{Desorption parameters}

The desorption process is one of the most important steps in the analysis of trapped analytes in an NTD system. The effects of the desorption time and the temperature were modelled and optimized by Design-Expert software using response surface methodology (RSM) and central composite design (CCD). In this study, the desorption time and temperature were investigated between 3 and 12 minutes and $270{ }^{\circ} \mathrm{C}$ and $390^{\circ} \mathrm{C}$, respectively. In previously reported studies, micro-extraction and NTD methods were used to select the desorption temperature range for the analysis of PAH compounds. ${ }^{43,44}$ For example, Soury et al. reported a zinc-based metal-organic framework as a sorbent in the NTD method for the extraction of polycyclic aromatic hydrocarbons in air with a desorption time and temperature range of $331-379{ }^{\circ} \mathrm{C}$ and 7-9 minutes, respectively. ${ }^{45}$ Also, Xiang-Feng et al. reported a MIL-53(Al) coating as a sorbent in the SPME method for the determination of polycyclic aromatic hydrocarbons by gas chromatography with a desorption time of 4 min ${ }^{46}$ In one study, they used a UiO-66 coating as a sorbent in the SPME method for the determination of polycyclic aromatic hydrocarbons, with a reported temperature and desorption time of $290^{\circ} \mathrm{C}$ and 10 minutes, respectively. ${ }^{43}$ In this work, the optimal desorption temperatures for benzo[a]pyrene, naphthalene,

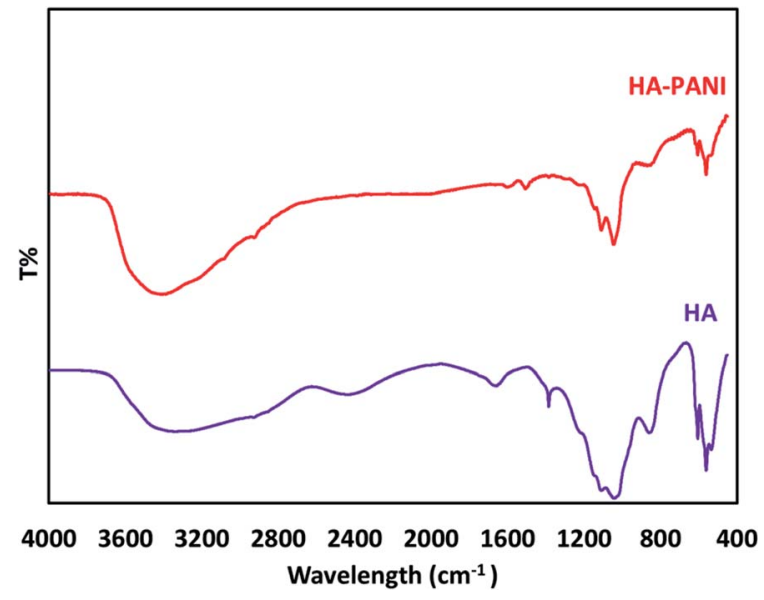

Fig. 4 The FT-IR spectra of the HA and PANIaHA structures. 
Table 1 Analysis of variance (ANOVA) results for the desorption parameters

\begin{tabular}{|c|c|c|c|c|c|}
\hline Parameters/analytes & Phenanthrene & Benzo $[a]$ pyrene & Naphthalene & Fluoranthene & Benzo[a]anthracene \\
\hline Temperature $\left({ }^{\circ} \mathrm{C}\right)$ & 362 & 384 & 356 & 368 & 375 \\
\hline Time (min) & 9.47 & 9.12 & 9.33 & 9.46 & 9.55 \\
\hline$R$-Squared & 0.84 & 0.84 & 0.86 & 0.83 & 0.82 \\
\hline Adj $R$-squared & 0.73 & 0.72 & 0.76 & 0.71 & 0.70 \\
\hline $\mathrm{SD}$ & 457.60 & 533.78 & 345.26 & 466.75 & 542.43 \\
\hline $\mathrm{CV}$ & 20.84 & 18.86 & 20.92 & 20.22 & 19.47 \\
\hline Press & $8.774 \times 10^{6}$ & $1.014 \times 10^{3}$ & $4.984 \times 10^{6}$ & $9.129 \times 10^{6}$ & $1.224 \times 10^{7}$ \\
\hline Lack of fit & 0.049 & 0.043 & 0.0535 & 0.049 & 0.052 \\
\hline
\end{tabular}

phenanthrene, fluoranthene and benzo $[a]$ anthracene are $384^{\circ} \mathrm{C}$, $356{ }^{\circ} \mathrm{C}, 362{ }^{\circ} \mathrm{C}, 368^{\circ} \mathrm{C}$ and $375{ }^{\circ} \mathrm{C}$, respectively. Also, the optimal desorption times are 9.12, 9.33, 9.47, 9.46 and $9.55 \mathrm{~min}$, respectively, which are consistent with similar studies. ${ }^{43-46}$
The obtained optimal desorption time for the analysis is higher than in other studies that used the solid phase microextraction method. ${ }^{11,46}$ This result can be related to the difference in the structures of SPME and NTD. In the SPME
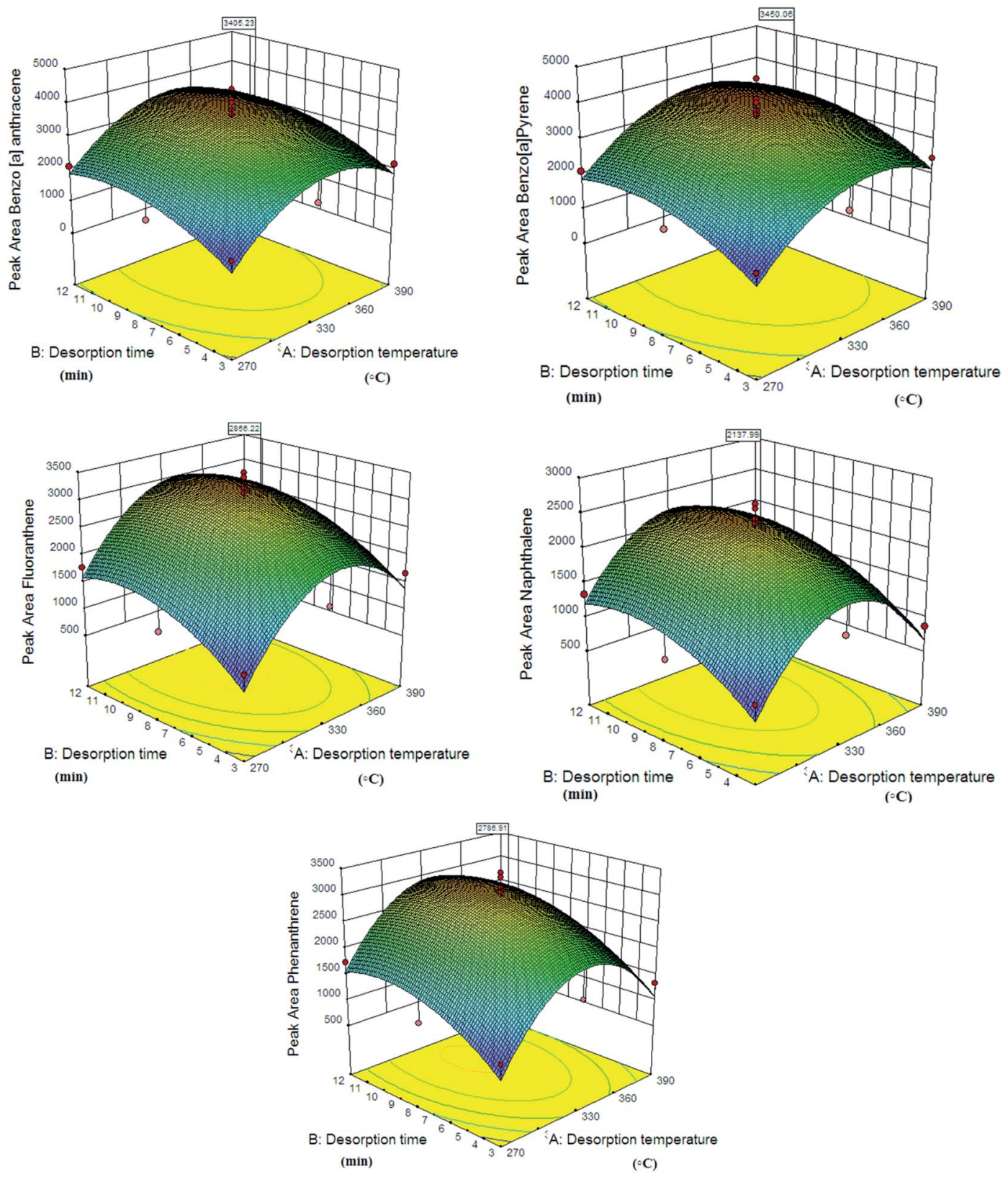

Fig. 5 Effects of desorption variables on the efficiency of NTD packed with PANI@HA in the sampling and analysis of PAH compounds. 
Table 2 The carryover effect of the NTD packed with PANI@HA adsorbent at different desorption times and temperatures ${ }^{a}$

\begin{tabular}{|c|c|c|c|c|c|c|}
\hline \multirow[b]{2}{*}{ Temp. $\left({ }^{\circ} \mathrm{C}\right)$} & \multirow[b]{2}{*}{ Time (min) } & \multicolumn{5}{|c|}{ Carryover effect for each analyte (\%) } \\
\hline & & Naphthalene & Phenanthrene & Fluoranthene & Benzo $[a]$ anthracene & Benzo $[a]$ pyrene \\
\hline 330 & 7.5 & 0.12 & 0.15 & 0.16 & 0.18 & 0.2 \\
\hline 330 & 12 & 0.10 & 0.10 & 0.11 & 0.11 & 0.12 \\
\hline 270 & 12 & 0.14 & 0.15 & 0.15 & 0.16 & 0.17 \\
\hline 330 & 3 & 0.21 & 0.22 & 0.27 & 0.29 & 0.33 \\
\hline 390 & 7.5 & ND & ND & ND & ND & ND \\
\hline 390 & 3 & 0.12 & 0.12 & 0.14 & 0.18 & 0.22 \\
\hline 270 & 7.5 & 0.18 & 0.19 & 0.19 & 0.20 & 0.21 \\
\hline 270 & 3 & 0.33 & 0.34 & 0.35 & 0.35 & 0.46 \\
\hline 390 & 12 & ND & ND & ND & $\mathrm{ND}$ & ND \\
\hline
\end{tabular}

method, the adsorbed analyte can be separated from the adsorbent surface in a shorter time due to the direct contact of the adsorbent with the hot carrier gas. The predicted modelling data and optimal time and temperature values by RSM are given in Table 1 . The calculated $R^{2}$ values in this model are $82-84$, indicating the appropriate response of the model. Fig. 5 shows the interactive effect of the desorption time and temperature on the NTD performance. Also, the chromatogram of the PAH compounds is shown in Fig. S1. $\dagger$

\subsection{Investigation of the breakthrough volume}

The breakthrough volume (BTV) phenomenon can occur when the amount of trapped analytes in the back of the NTD is greater by $10 \%$ than the amount of trapped analytes in the front of the NTD. The sampling time was increased to 8 hours with increasing of the sampled air volume because the NTD

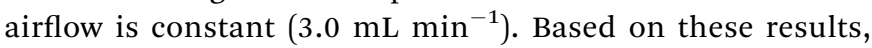

Table 3 Relative standard deviation percentages for investigation of the reproducibility and repeatability of NTD:PANI@HA for extraction of $\mathrm{PAH}$ compounds

\begin{tabular}{|c|c|c|c|c|c|c|c|c|c|}
\hline \multirow[b]{2}{*}{ Analytes } & \multicolumn{5}{|c|}{$\begin{array}{l}\text { RSD \% for a NTD at different } \\
\text { concentrations }\left(\mathrm{mg} \mathrm{m}^{-3}\right)\end{array}$} & \multicolumn{4}{|c|}{$\begin{array}{l}\text { RSD\% for different } \\
\text { NTDs at a constant } \\
\text { concentration }\end{array}$} \\
\hline & 5 & 10 & 30 & 50 & 100 & & TD1 & NTD2 & NTD3 \\
\hline \multirow[t]{2}{*}{ Naphthalene } & 4.3 & 5.8 & 9.1 & 9.9 & 8.6 & 4. & & 6.4 & 10.5 \\
\hline & & \multicolumn{5}{|c|}{$\begin{array}{l}\text { RSD } \% \text { for a NTD at } \\
\text { different concentrations } \\
\left(\mathrm{mg} \mathrm{m}^{-3}\right)\end{array}$} & \multicolumn{3}{|c|}{$\begin{array}{l}\text { RSD\% for different } \\
\text { NTDs at a constant } \\
\text { concentration }\end{array}$} \\
\hline Analytes & & 0.01 & 0.02 & 0.05 & 0.07 & 1 & NTD1 & NTD2 & NTD3 \\
\hline Phenanthrene & & 3.9 & 4.5 & 3.2 & 5.8 & 4.4 & 10.7 & 4.8 & 3.8 \\
\hline Benzo $[a]$ pyrene & & 2.8 & 3.9 & 5.1 & 4.3 & 4.9 & 5.5 & 11.3 & 5.9 \\
\hline Fluoranthene & & 3.2 & 2.7 & 4.8 & 4.1 & 4.3 & 8.8 & 10.1 & 8.5 \\
\hline Benzo $[a]$ anthrac & cene & 2.9 & 3.3 & 4.1 & 5.6 & 3.4 & 9.4 & 7.6 & 4.7 \\
\hline
\end{tabular}

BTV was not seen even after 8 hours of sampling with the proposed NTD.

\subsection{Carryover effect}

The carryover effect depends on two parameters: desorption time and temperature. Soury et al. did not observe any carryover effect for the sampling of PAHs by the Zn-MOF adsorbent at the desorption time and temperature of $9 \mathrm{~min}$ and $379{ }^{\circ} \mathrm{C}$, respectively. ${ }^{45}$ Moreover, in a similar study, the carryover effect was not observed for the sampling of polycyclic aromatic hydrocarbons by the MIL-53(Al) coating in the SPME method with a desorption time of $4 . \mathrm{min}^{46} \mathrm{In}$ this study, carryover was not observed at the optimal desorption time and temperature. However, the carryover effect was determined for the performed experiments with different desorption times and temperatures. These results are shown in Table 2 . As can be seen in Table 2, the maximum carryover effect is related to the desorption temperature and time of $270{ }^{\circ} \mathrm{C}$ and 3 minutes, respectively.

\subsection{Method precision}

To evaluate the precision, repeatability and reproducibility parameters, they were determined in terms of the RSD percentage. The repeatability for naphthalene at concentrations of 5.0, 10.0, 30.0, 50.0 , and $100.0 \mathrm{mg} \mathrm{m}^{-3}$ and for phenanthrene, benzo $[a]$ pyrene, fluoranthene and benzo[a]anthracene at concentration levels of

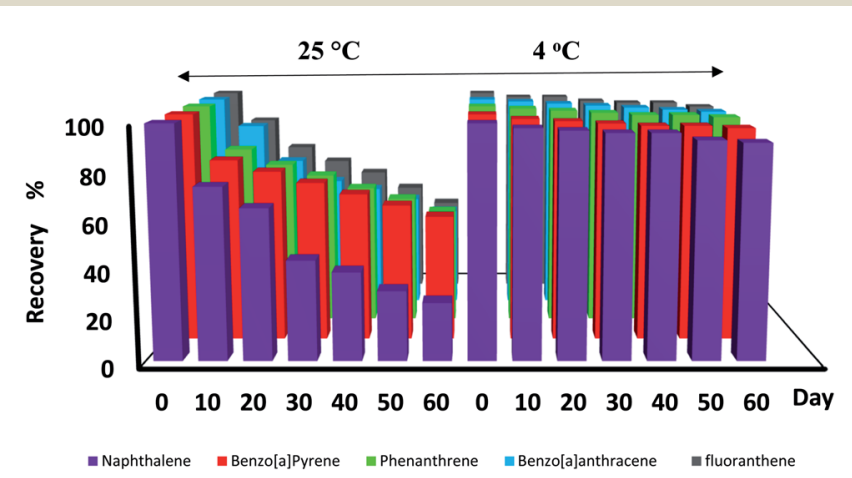

Fig. 6 Storage times of PAH compounds trapped by NTD:PANIaHA from 1 day to 60 days at $4{ }^{\circ} \mathrm{C}$ and $25^{\circ} \mathrm{C}$. 
Table 4 Comparison of NTD:PANI@HA with other methods for sampling and analysis of PAH compounds ${ }^{a}$

\begin{tabular}{|c|c|c|c|c|c|c|c|c|c|c|c|c|}
\hline \multirow[b]{2}{*}{ Compounds } & \multicolumn{3}{|c|}{ Current method (ng mL ${ }^{-1}$ ) } & \multicolumn{3}{|c|}{$\begin{array}{l}\text { NTD/Zn-MOF GC/air } \\
\left(\mathrm{mg} \mathrm{m}^{-3}\right)^{45}\end{array}$} & \multicolumn{3}{|c|}{$\begin{array}{l}\text { SPME/PDMS GC-MS/ } \\
\text { air (ng) })^{49}\end{array}$} & \multicolumn{3}{|c|}{$\begin{array}{l}\text { MSPE/ZIF-7/GC-MS air- } \\
\text { water }\left(\mathrm{ng} \mathrm{L}^{-1}\right)^{50}\end{array}$} \\
\hline & LOD & LOQ & LDR & LOD & LOQ & LDR & LOD & LOQ & LDR & LOD & LOQ & LDR \\
\hline Naphthalene & 0.002 & 0.021 & $0.002-398$ & 0.011 & 0.04 & $0.01-262$ & 0.02 & 0.05 & NR & NR & NR & NR \\
\hline Phenanthrene & 0.001 & 0.051 & $0.001-8$ & 0.021 & 0.07 & $0.021-1$ & 0.92 & 3.06 & NR & 5.79 & 19.2 & $0.05-5$ \\
\hline Benzo $[a]$ pyrene & 0.002 & 0.022 & $0.002-2$ & 0.01 & 0.03 & $0.01-0.5$ & 0.75 & 3.46 & NR & 3.32 & 11.1 & $0.05-5$ \\
\hline
\end{tabular}

${ }^{a}$ NR: not reported.

0.01, 0.02, 0.05, 0.07 and $1.0 \mathrm{mg} \mathrm{m}^{-3}$ was examined. The obtained results are shown in Table 3 . The calculated RSD for the proposed NTD is between 2.8-9.9, which indicates appropriate precision of the sampling and analysis system in this study.

To evaluate the reproducibility of the proposed method, three different NTDs with the same concentration $\left(50.0 \mathrm{mg} \mathrm{m}^{-3}\right.$ for naphthalene and $0.2 \mathrm{mg} \mathrm{m}^{-3}$ for phenanthrene, benzo[ $\left.a\right]$ pyrene, fluoranthene and benzo[ $a]$ anthracene) were used in the optimal desorption conditions (Table 3). The precision of the samples was also evaluated at an acceptable level, which indicates appropriate reproducibility of the NTDs. It should be noted that there are no data about the repeatability and reproducibility of the NIOSH 5515 method for sampling of PAHs. ${ }^{47}$

\subsection{Storage time}

Fig. 6 indicates the results of the storage time experiment. As shown in the diagram, the concentrations of the analytes (especially naphthalene) decreased below $70 \%$ at $25{ }^{\circ} \mathrm{C}$ after 20 days. On the other hand, there was no significant change in the peak surface area of the studied analytes at a temperature of $4{ }^{\circ} \mathrm{C}$ after 60 days. Therefore, the desired analytes can be stored in the proposed NTD for up to 60 days at refrigerator temperature. According to the NIOSH method for polyaromatic hydrocarbons, the sample should be protected from ultraviolet and heat radiation; however, the storage time is not specified in this method. ${ }^{47}$ Also, in the EPA TO-13A technique, the samples can be stored at $4{ }^{\circ} \mathrm{C}$ for 7 days. ${ }^{48}$

Table 5 The amounts of PAH compounds in air from a high-traffic area using the NTD:PANICHA and NIOSH 5515 methods

\begin{tabular}{|c|c|c|c|c|}
\hline \multirow[b]{2}{*}{ Analyte } & \multicolumn{2}{|l|}{ NTD:PANI@HA } & \multicolumn{2}{|c|}{ NIOSH 5515:XAD2 } \\
\hline & $\begin{array}{l}\text { Concentration } \\
\left(\mathrm{mg} \mathrm{m}^{-3}\right)\end{array}$ & RSD & $\begin{array}{l}\text { Concentration } \\
\left(\mathrm{mg} \mathrm{m}^{-3}\right)\end{array}$ & RSD \\
\hline Naphthalene & 11.3 & 11.2 & 9.1 & 12.5 \\
\hline Phenanthrene & 0.2 & 8.7 & 0.13 & 6.4 \\
\hline Benzo $[a]$ pyrene & 0.13 & 6.9 & 0.09 & 8.8 \\
\hline Fluoranthene & 0.14 & 5.8 & 0.09 & 7.6 \\
\hline $\begin{array}{l}\text { Benzo }[a] \\
\text { anthracene }\end{array}$ & 0.12 & 7.3 & 0.08 & 5.9 \\
\hline
\end{tabular}

\subsection{Validation of the method}

The LOD and LOQ parameters for the NTD method were determined based on the signal-to-noise ratios of 3 to 1 and 10 to 1 , respectively. The obtained results are in the range of 001003 and $0.021-0.051 \mathrm{ng} \mathrm{mL}{ }^{-1}$, respectively. The reported LOD by the NIOSH method (5515) for the analysis of PAH compounds is in the range of $0.3-0.5 \mu \mathrm{g}$ per sample. The LOD value in this study is lower than that of the standard NIOSH method. ${ }^{47}$ Therefore, the suggested NTD offers high sensitivity for the determination of PAH compounds.

The LDR as another examined parameter for the NTD:PANI@HA method showed a linear range of up to $262.0 \mathrm{ng} \mathrm{mL} \mathrm{m}^{-1}$, which expresses the high adsorption capacity of the desired adsorbent. According to Table 4, the proposed NTD method shows a lower LOD and LOQ and higher linear range. Therefore, NTD:PANI@HA can be used to determine the concentrations of PAHs in a wide range in workplace air. Also, the accuracy parameters were investigated by comparison of the results obtained using the NTD:PANI@HA and XAD-2 methods at different concentrations for benzo[a]pyrene (Fig. S2 $\dagger$ ). The calculated $R^{2}$ values in the range of $0.98-0.99$ proved a good correlation coefficient between the two methods.

\subsection{Field measurements}

After the employment of the NTD:PANI@HA method in laboratory-scale studies, the efficiency and performance of the method were examined in real conditions. To achieve this goal, samples of $\mathrm{PAH}$ compounds from regional air with high traffic and congestion of gasoline vehicles were evaluated, and the obtained results were compared with the NIOSH 5515 method (Table 5). It should be noted that in the NTD method, all of the adsorbed analytes were injected into the GC without dilution because of the solvent-free conditions. Therefore, the sensitivity of this method is higher than those of the usual methods. ${ }^{51-56}$

\section{Conclusion}

In this study, we attempted to provide NTD:PANI@HA as a promising method for the sensitive and efficient sampling and analyzing of $\mathrm{PAH}$ compounds for the first time. To achieve this goal, polyaniline-doped nano-hydroxyapatite as an efficient absorbent was synthesized and characterized by the PXRD, FE- 
SEM, and FT-IR techniques. Optimization of the adsorbent parameters was performed using the RSM and CCD methods. On the bench scale, studies of sampling and analysis parameters such as carryover effect, storage time, accuracy, and precision of the method presented suitable results. Additionally, the NTD packed with polyaniline-doped nano-hydroxyapatite was employed on the field scale to assess occupational and environmental exposure of PAHs. According to the obtained results, NTD:PANI@HA has a good adsorption capacity and high linear range. Comparison of the NTD technique with the NIOSH standard method proved that the proposed method is more suitable for sampling and analysis of PAH compounds in air and with a higher repeatability and sensitivity. The main problem with using NTD as a sampler is the absorption loading, which can lead to a drop in pressure and increase the sampling time. To address this drawback, it is recommended to use different adsorbent/crumb glass ratios in the preliminary tests and consider the best ratio for the main tests.

\section{Conflicts of interest}

There are no conflicts to declare.

\section{References}

1 M. Guo, Z. Gong, X. Li, G. Allinson, J. Rookes and D. Cahill, Ecotoxicol. Environ. Saf., 2017, 140, 191-197.

2 K. H. Kim, S. A. Jahan, E. Kabir and R. J. C. Brown, Environ. Int., 2013, 60, 71-80.

3 E. Gregoris, E. Argiriadis, M. Vecchiato, S. Zambon, S. De Pieri, A. Donateo, D. Contini, R. Piazza, C. Barbante and A. Gambaro, Sci. Total Environ., 2014, 476-477, 393-405.

4 H. I. Abdel-Shafy and M. S. M. Mansour, Egypt. J. Pet., 2016, 25, 107-123.

5 K. Peltonen and T. Kuljukka, J. Chromatogr. A, 1995, 710, 93108.

6 D. L. Poster, M. M. Schantz, L. C. Sander and S. A. Wise, Anal. Bioanal. Chem., 2006, 386, 859-881.

7 A. Firoozichahak, A. Bahrami, F. Ghorbani Shahna, S. Alizadeh, D. Nematollahi and M. Farhadian, Int. J. Environ. Anal. Chem., 2019, 1-18.

8 A. Firoozichahak, A. Bahrami, F. Ghorbani Shahna, S. Alizadeh, D. Nematollahi and M. Farhadian, J. Sep. Sci., 2020, 43, 1011-1018.

9 A. A. Alinaghi Langari, A. Firoozichahak, S. Alizadeh, D. Nematollahi and M. Farhadian, RSC Adv., 2020, 10, 13562-13572.

10 S. Maghsoudi and E. Noroozian, Chromatographia, 2012, 75, 913-921.

11 M. J. Rocha, E. Rocha, C. Cruzeiro, P. C. Ferreira and P. A. Reis, J. Chromatogr. Sci., 2011, 49, 695-701.

12 F. F. Lei, J. Y. Huang, X. N. Zhang, X. J. Liu and X. J. Li, Chromatographia, 2011, 74, 99-107.

13 H. C. Menezes, M. J. N. Paiva, R. R. Santos, L. P. Sousa, S. F. Resende, J. A. Saturnino, B. P. Paulo and Z. L. Cardeal, Microchem. J., 2013, 110, 209-214.
14 J. A. Koziel, M. Odziemkowski and J. Pawliszyn, Anal. Chem., 2001, 73, 47-54.

15 P. Přikryl, R. Kubinec, H. Jurdáková, J. Ševčík, I. Ostrovský, L. Soják and V. Berezkin, Chromatographia, 2006, 64, 65-70.

16 H. L. Lord, W. Zhan and J. Pawliszyn, Anal. Chim. Acta, 2010, 677, 3-18.

17 I. Ueta, T. Mitsumori, Y. Suzuki, S. Kawakubo and Y. Saito, J. Chromatogr. A, 2015, 1397, 27-31.

18 K. Kędziora and W. Wasiak, J. Chromatogr. A, 2017, 1505, 117.

19 Z. Ghalichi Zave, A. Bahrami, F. Ghorbani Shahna and M. Farhadian, J. Chromatogr. A, 2019, 1602, 74-82.

20 S. Soury, A. Bahrami, S. Alizadeh, F. Ghorbani Shahna and D. Nematollahi, Saf. Health Work, 2020, 10, 173-188.

21 H. Cao, L. Zhang, H. Zheng and Z. Wang, J. Phys. Chem. C, 2010, 114, 18352-18357.

22 J. Feng, M. Sun, J. Li, L. Xu, X. Liu and S. Jiang, J. Chromatogr. A, 2011, 1218, 3601-3607.

23 S. Alizadeh and D. Nematollahi, J. Am. Chem. Soc., 2017, 139, 4753-4761.

24 S. Alizadeh and D. Nematollahi, Sci. Rep., 2019, 9, 1-13.

25 M. Ibrahim, M. Labaki, J. M. Giraudon and J. F. Lamonier, J. Hazard. Mater., 2020, 383, 121139.

26 A. Fihri, C. Len, R. S. Varma and A. Solhy, Coord. Chem. Rev., 2017, 347, 48-76.

27 S. R. Shepard, C. Brickman-Stone, J. L. Schrimsher and G. Koch, J. Chromatogr. A, 2000, 891, 93-98.

28 T. Li and Y. Q. Feng, Talanta, 2009, 80, 889-894.

29 Z. Shan, X. Li, Y. Gao, X. Wang, C. Li and Q. Wu, Anal. Biochem., 2012, 425, 125-127.

30 W. Wei, X. Zhang, J. Cui and Z. Wei, J. Liq. Chromatogr. Relat. Technol., 2010, 33, 1335-1349.

31 S. Yu, J. Geng, P. Zhou, J. Wang, X. Chen and J. Hu, J. Chromatogr. A, 2008, 1183, 29-37.

32 F. Rahmani, A. Es-haghi, M. R. M. Hosseini and A. Mollahosseini, Microchem. J., 2019, 145, 942-950.

33 M. M. Abolghasemi, S. Parastari and V. Yousefi, Microchim. Acta, 2016, 183, 241-247.

34 L. Jia, X. Wei, L. Lv, X. Zhang, X. Duan, Y. Xu, K. Liu and J. Wang, Electrochim. Acta, 2018, 280, 315-322.

35 N. Aboudzadeh, M. Imani, M. A. Shokrgozar, A. Khavandi, J. Javadpour, Y. Shafieyan and M. Farokhi, J. Biomed. Mater. Res., Part A, 2010, 94, 137-145.

36 L. Huixia, L. Yong, L. Lanlan, T. Yanni, Z. Qing and L. Kun, Mater. Sci. Eng., C, 2016, 59, 438-444.

37 B. Butoi, A. Groza, P. Dinca, A. Balan and V. Barna, Polymers, 2017, 9, 732 .

38 M. A. Bezerra, R. E. Santelli, E. P. Oliveira, L. S. Villar and L. A. Escaleira, Talanta, 2008, 76, 965-977.

39 T. Thanpitcha, A. Sirivat, A. M. Jamieson and R. Rujiravanit, Carbohydr. Polym., 2006, 64, 560-568.

40 X. Zhang, Y. B. Li, Y. Zuo, G. Y. Lv, Y. H. Mu and H. Li, Composites, Part A, 2007, 38, 843-848.

$41 \mathrm{H}$. Wang, Y. Li, Y. Zuo, J. Li, S. Ma and L. Cheng, Biomaterials, 2007, 28, 3338-3348.

42 Y. M. Hao, C. Man and Z. B. Hu, J. Hazard. Mater., 2010, 184, 392-399. 
43 J. Gao, C. Huang, Y. Lin, P. Tong and L. Zhang, J. Chromatogr. A, 2016, 1436, 1-8.

44 Z. Ghalichi Zave, A. Bahrami, F. Ghorbani Shahna and M. Farhadian, Application of a needle trap device packed with XAD-2 polyaniline composite for sampling naphthalene and phenanthrene in air, J. Chromatogr. A, 2019, 1602, 74-82.

45 S. Soury, A. Bahrami, S. Alizadeh, F. Ghorbani Shahna and D. Nematollahi, Microchem. J., 2019, 148, 346-354.

46 X. F. Chen, H. Zang, X. Wang, J. G. Cheng, R. S. Zhao, C. G. Cheng and X. Q. Lu, Analyst, 2012, 137, 5411-5419.

47 National Institute for Occupational Safety and Health (NIOSH), Polynuclear Aromatic Hydrocarbons By Gc Method 5515, 4th edn, 15 August 1994, pp. 2-7.

48 U.S. Environmental Protection Agency (EPA), Determination of Polycyclic Aromatic Hydrocarbons (PAHs) in Ambient Air Using Gas Chromatography/Mass Spectrometry (GC/MS), Method TO-13A, 1999, EPA/625/R-96/010b.
49 H. C. Menezes and Z. De Lourdes Cardeal, J. Chromatogr. A, 2011, 1218, 3300-3305.

50 S. Zhang, W. Yao, J. Ying and H. Zhao, J. Chromatogr. A, 2016, 1452, 18-26.

51 J. B. Pawliszyn, US Pat. 6481301 B2, 2002.

52 A. Poormohammadi, A. Bahrami, A. Ghiasvand, F. G. Shahna and M. Farhadian, Microchem. J., 2018, 143, 127-132.

53 P. Trefz, S. Kischkel, D. Hein, E. S. James, J. K. Schubert, W. Miekisch, S. Kischkel, J. K. Schubert, W. Miekisch, E. S. James, P. Trefz, S. Kischkel, D. Hein, E. S. James, J. K. Schubert and W. Miekisch, J. Chromatogr. A, 2012, 1219, 29-38.

54 I. Y. Eom, A. M. Tugulea and J. Pawliszyn, J. Chromatogr. A, 2008, 1196-1197, 3-9.

55 Y. Gong, I. Y. Eom, D. W. Lou, D. Hein and J. Pawliszyn, Anal. Chem., 2008, 80, 7275-7282.

56 I. Y. Eom, A. M. Tugulea and J. Pawliszyn, J. Chromatogr. A, 2008, 1196-1197, 3-9. 